\title{
From REM to orexin: clinical progress in narcolepsy - was it worth the wait? was it worth the "weight?"
}

\author{
Do sono REM à orexina: evolução clínica em narcolepsia - valeu a pena a espera? \\ Valeu a pena o "peso"?" \\ Kenneth Clayton SASSOWER ${ }^{1,2}$
}

\footnotetext{
${ }^{1}$ Massachusetts General Hospital, Division of Sleep Medicine, Boston, Massachusetts, USA. ${ }^{2}$ Massachusetts General Hospital, Division of Clinical Neurophysiology, Boston, Massachusetts, USA. KCS (iD) https://orcid.org/00000002-7283-0834

Correspondence: Kenneth Clayton Sassower; Email: ksassower@mgh.harvard.edu. Conflict of interest: There is no conflict of interest to declare. Received on August 31, 2021; Accepted on August 31, 2021.
}

$\mathrm{T}$ he earliest description of the narcoleptic condition was likely first described by Thomas Willis approximately four centuries ago, in his report of a patient with an exceptionally hypersomnolent predisposition, and who was prone to bouts of extreme daytime sleepiness ${ }^{1}$. It was perhaps not until 1880, when Gelineau actually coined the term "narcolepsy" (derived from the Greek "lepsis", which literally means "attack," or "to seize"), that the paroxysmal nature of these diurnal bouts of hypersomnolence was highlighted ${ }^{2}$. At around the same time as Gelineau, there were case reports by Westphal and Fisher and others who first linked the hypersomnolent condition to other clinical features, including acute bouts of diffuse loss of motor tone suggestive of cataplexy. At around the turn of the 20th century, William Gowers sought to differentiate the episodic bouts of daytime sleepiness from more protracted bouts of debilitating hypersomnolence noted in certain neurodegenerative disorders ${ }^{3}$. In 1928, Wilson helped to add the clinical feature of sleep paralysis to the condition ${ }^{4}$, and it was perhaps not until three decades later that Yoss and Daly, over at the Mayo Clinic, described a full tetrad of clinical symptoms associated with narcolepsy; i.e., including extreme bouts of daytime sleepiness, diurnal cataplexy, sleep paralysis and hypnagogic hallucinations ${ }^{5}$. In the late 1950 s and in the early 1960s, the time was ripe for neurophysiologic investigations to better characterize the condition. These investigations included the actual documentation of REM onset in patients with acute narcoleptic attacks by Vogel ${ }^{6}$, and the electroclinical description of narcolepsy as a primary REM boundary and REM dissociative condition by Aserinsky and Kleitman and Dement in their seminal work on the subject ${ }^{7}$; their works ultimately lead to the development of the Multiple Sleep Latency Test (MSLT) as the standard diagnostic tool in narcolepsy. This period of time also served as a backdrop for burgeoning interest in sleep disorders in general, and in narcolepsy and cataplexy in particular, leading to worldwide interest in research and the development of multiple academic and clinical sleep centers investigating the condition throughout the world. At around the same time, narcolepsy was discovered across various canine species, including Beagles, Labradors and Dobermans ${ }^{8}$. In Labradors, it was felt that the condition was associated with a single autosomal recessive gene. Around the same time, there was also interest in specific HLA haplotypes, most notably the HLA-DQB1-0602 gene located on chromosome 6, which has been associated with narcolepsy and cataplexy in up to $90 \%$ of affected individuals - leading to the clinical suspicion that narcolepsy was an autoimmune disorder 9 . Over the ensuing years, management of patients with narcolepsy and cataplexy was bolstered by treatment options that not only improved level of daytime alertness and attention in susceptible individuals, but also helped to combat associated clinical features of narcolepsy, such as diurnal cataplexy. One specific treatment, Sodium Oxybate therapy, was deemed to be a primary clinical treatment for patients with both narcolepsy and cataplexy, specifically targeting GHB and GABA receptors in the brain. At the turn of the century, perhaps the most significant and innovative clinical research specifically targeting the underpinnings of the narcoleptic condition came in two separate laboratories, which helped to pinpoint an isolated neuropeptide which went by the names of orexin/hypocretin ${ }^{10}$, and which had a predilection for the perifornical area and lateral hypothalamus, and for which the drop off of these polypeptide neurons resulted in reproduction of narcoleptic and cataplectic symptoms in rodents ${ }^{11}$. 
Given the fact that the term "orexin" is derived from the Greek which means "appetite," it was just a matter of time when researchers would look at this putative neuropeptide not only for its potential role in regulation of sleep and wakefulness, but also for its role in regulation of appetite and satiety. Studies over the past couple of decades have demonstrated an association between orexin deficiency in narcoleptic humans and the presence of abdominal obesity. The narcoleptic patients in the study tended to have an increased waist circumference, reflective of excessive fat storage in abdominal depots. When contrasted to patients with other disorders of diurnal hypersomnolence not due to narcolepsy (e.g., idiopathic central nervous system hypersomnolence), it has been felt that the latter subgroup of non-hypersomnolent patients had a lower BMI than the narcoleptic subgroup - perhaps adding fuel to the fire that it is the orexin deficiency itself (and not the inactive and sedentary lifestyle of some hypersomnolent patients) accounting for excessive body fat in these susceptible orexin-deficient narcoleptic patients ${ }^{12}$.

Enter the current authors Giselle de Martin Truzzi, Maria Fernand Naufel, Sergio Tufik, and Fernando Morgadinho Coelho, and their scholarly work entitled "Narcolepsy: The impact of aging, deficiency of hypocretin and years of formal education in olfaction function and abdominal obesity"13. In my opinion, this article reflects the "new generation" of clinical concerns regarding this intriguing and fascinating primary sleep disorder of diurnal hypersomnolence. It seems that we no longer have the liberty of thinking about this condition in the quasi-monolithic manner our devoted forefathers were once forced to. When we approach our clinical patients with narcolepsy, we now have to consider the potential health risks of this condition in the context of intercurrent sleep-disordered breathing, as well as the higher associated rates of diabetes, hypertension, hypercholesterolemia and hypertriglyceridemia.

Given the rapid and vast clinical progress that has occurred over the expanse of an half-century ${ }^{14}$ - from the time REM sleep was discovered until the pathogenesis of narcolepsy was unravelled - we are left to ask ourselves the following question: Was it worth the wait? Yes, and undeniably so! In addition, and given our newer understanding regarding the relative role that orexin deficiency plays in the development of abdominal obesity (and, in turn, its potential effect on an host of some of the most common systemic disorders now plaguing our human existence) - we are left to ask ourselves the following additional questio: Was it worth the "weight?" Once again, we would have to respond most decidedly and most definitively in the affirmative.

\section{REFERENCES}

1. Lennox WC. Thomas Willis on Narcolepsy. Arch Neur Psych. 1939 Feb;41(2):348-51.

2. Gelineau J. De la narcolepsie. Gazette des Hopitaux Civils et Militaires1880;53:626-8(Part a); 54:635-7(Part b).

3. Gowers WR. Borderland of Epilepsy. Philadelphia (US): Blakiston; 1907.

4. Wilson SAK. The narcolepsies. Brain. 1928 Mar;51:63-109. https:// psycnet.apa.org/doi/10.1093/brain/51.1.63

5. Yoss RE, Daly DD. Criteria for the diagnosis of the narcoleptic syndrome. Proc Staff Meeting Mayo Clinic. 1957 Jun;32(12):320-8.

6. Vogel G. Studies in the psychophysiology of dreams III. The dream of narcolepsy. Arch Gen Psychiat. 1960 Oct;3:421-8. https://doi. org/10.1001/archpsyc.1960.01710040091011

7. Kleitman N. Sleep and Wakefulness. London (UK): University of Chicago Press; 1963.

8. Baker TL, Foutz AS, McNerney V, Mitler MM, Dement WC. Canine model of narcolepsy. Exp Neurol. 1982;75(3):729-42. https://doi. org/10.1016/0014-4886(82)90038-3
9. Matsuki K, Grumet FC, Lin X, Gelb M, Guilleminault C, Dement WC, Mignot E. DQ (rather than DR) gene marks susceptibility to narcolepsy. Lancet. 1992 Apr;339(8800):1052. https://doi. org/10.1016/0140-6736(92)90571-j

10. Nishino S, Ripley B, Overeem S, Lammers GJ, Mignot E. Hypocretin (orexin) transmission in human narcolepsy. Lancet. 2000 Jan;355(9197):39-40.

11. Nishino S, Kanbayashi T. Symptomatic narcolepsy, cataplexy and hypersomnia, and their implication in the hypothalamic hypocretin/ orexin system. Sleep Med Rev. 2005 Aug;9(4):269-310. https://doi. org/10.1016/j.smrv.2005.03.004

12. Kok, SW, Overeem S, Visscher TLS, et al. Hypocretin deficiency in narcoleptic humans is associated with abdominal obesity. Obes Res. 2012;11(9):1147-54. https://doi.org/10.1038/oby.2003.156

13. Truzzi GM, Naufel MF, Tufik S, Coelho FM. Narcolepsy: the impact of aging, hypocretin deficiency, and years of formal education in olfactory function and abdominal obesity. Arq Neuropsiquiatr. 2021;79(9):808-15. https://doi.org/10.1590/0004-282X-ANP-2020-0352

14. Todman D. Narcolepsy: A historic review. Int J Neurology. 2007;9(2). https://ispub.com/lJN/9/2/7361 